\title{
Karakteristik Petani, Usaha Tani dan Pengetahuan Tentang Pestisida dan Pengendalian Hama Terpadu di Kabupaten Garut
}

\author{
Farmer Characteristics, Farming Business and Knowledge of Integrated \\ Pesticides and Pest Control in Garut Regency
}

\author{
Siti Syarah Maesyaroh ${ }^{1}$, Tazkia Nur Arifah ${ }^{1}$, \\ ${ }^{1}$ Program Studi Agroteknologi - Fakultas Pertanian Universitas Garut \\ Jl. Raya Samarang No.52A, Tarogong Kaler, Kabupaten Garut, Jawa Barat 44151 \\ e-mail: syarah.esya@gmail.com
}

\begin{abstract}
ABSTRAK
Kabupaten Garut merupakan salah satu produsen tanaman hortikultura di Indonesia Penelitian ini bertujuan untuk mengetahui karakteristik petani dan usaha tani serta pegetahuan petani akan pestisida dan PHT. Penelitian dilaksanakan di Kabupaten Garut. Penelitian dilaksanakan pada bulan Desember 2019. Penelitian ini menggunakan metode survei dan dirancang dengan metode survei deksriptif yang menjelaskan karakteristik petani dan usaha tani serta pengetahuan akan pestisida dan prinsip PHT. Hasil penelitian menunjukkan bahwa Pengetahuan petani akan PHT masih minim hal ini dibuktikan dengan hanya sebanyak 33,33\% petani yang tahu akan PHT dan sisanya sebanyak 66,67\% tidak tahu akan PHT. Hal tersebut dapat diatasi dengan Sekolah Lapang Pengendalian Hama Terpadu (SLPHT) dengan memperkenalkan tanaman refugia kepada petani karena sebanyak $72,22 \%$ responden tidak tahu akan tanaman refugia.
\end{abstract}

Kata Kunci: PHT, Refugia, SLPHT

\begin{abstract}
Garut is one of the producers of horticultural crops in Indonesia. The study aims to determine the characteristics of farmers and farming businesses and farmers' knowledge of pesticides and IPM. The study was conducted in Garut. The study was conducted in December 2019. The study used a survey method and was designed with a descriptive survey method that explained the characteristics of farmers and farming as well as knowledge of pesticides and IPM principles. The results showed that the knowledge of farmers about IPM is still minimal, this is evidenced by only $33.33 \%$ of farmers who know about IPM and the remaining $66.67 \%$ do not know about IPM. This can be overcome by the Integrated Pest Management Field School (IPMFS) by introducing refugia plants to farmers because as much as $72.22 \%$ of respondents did not know about refugia plants
\end{abstract}

Keyword: IPM, IPMFS, Refugia 


\section{PENDAHULUAN}

Teknologi pertanian yang semakin berkembang menyebabkan dampak modernisasi pertanian, hal tersebut menyebabkan petani-petani di dunia khususnya Indonesia menggunakan varietas yang unggul, pestisida dan pupuk kimia dalam aktivitas budidaya pertanian yang dilakukannya.

Kabupaten Garut, Jawa Barat merupakan salah satu produsen tanaman hortikultura di Indonesia, dalam budidaya tanaman hortikultura terdapat beberapa kendala diantaranya adalah keterserdiaan benih bermutu yang terbatas, serangan OPT dan teknik budidaya yang masih dilakukan secara konvensional.

Permasalahan utama pada budidaya tanaman hortikultura adalah serangan OPT yang cukup tinggi. Pengendalian yang dilakukan oleh petani masih bersifat konvensional, dimana pengendalian hama dan penyakit tanaman dilakukan dengan penyemprotan pestisida kimia yang seringkali dilakukan tanpa dosis dan waktu yang tepat. Penggunaan pestisida yang terus menerus dapat menyebabkan dampak negatif terhadap lingkungan, petani, tanaman dan masyarakat yang mengkonsumsi produk pertanian. Menurut Yuantri et al., (2013) penggunaan pestisida yang dilakukan oleh petani mengakibatkan keracunan bagi petani, residu pestisida mengendap dalam tanah serta pestisida yang disemprotkan pada tanaman nantinya akan diserap oleh tanaman melalui daun, batang dan akar tanaman.

Menurut Rauf (1999) pengendalian kimiawi menggunakan pestisida yang diterapkan petani bukanlah strategi pengendalian yang berkelanjutan baik dalam ekologis maupun ekonomis, permasalahan penggunaan pestisida kimia tersebut menuntut adanya cara pengendalian OPT yang ekonomis dan menguntungkan petani, lingkungan maupun konsumen produk pertanian.

Konsep pengendalian PHT merupakan salah satu upaya pemerintah untuk mengurangi pengguanaan pestisida kimia. Pemerintah telah mengeluarkan kebijakan bahwa program perlindungan tanaman dilaksanakan dengan sistem pengendalian hama terpadu (PHT). Pendekatan sistem PHT meliputi budidaya tanaman sehat, pemanfaatan musuh alami, pemantauan rutin, dan petani sebagai pakar PHT (Duriat et al., 2006). PHT berdampak positif terhadap ekonomi petani karena pengurangan penggunaan pestisida yang menyebabkan menurunnya biaya 
produksi dan secara tidak langsung meningkatkan pengetahuan dan keterampilan petani sebagai pakar PHT.

\section{METODE PENELITIAN}

Penelitian ini menggunakan metode survei dan dirancang dengan metode survei deksriptif yang menjelaskan karakteristik petani dan usaha tani serta pengetahuan akan pestisida dan prinsip PHT. Data diambil menggunakan kuesioner, wawancara dan observasi. Instrumen yang digunakan dalam penelitian ini adalah karakteristik petani dan usaha tani diukur melalui umur, tingkat pendidikan formal, status kepemilikan lahan dan luas lahan. Penelitian dilakukan di Kabupaten Garut dengan mengambil sampel responden secara acak. Penelitian dilakukan pada bulan Desember 2019.

\section{HASIL DAN PEMBAHASAN}

\section{Karakteristik Petani dan Usaha Tani}

Karakteristik petani merupakan unsur yang melekat pada diri petani seperti umur, Pendidikan petani sedangkan karakteristik usaha tani adalah unsur unsur yang berhubungan dengan usaha tani yang dijalankan oleh petani tersebut. Berdasarkan hasil pegamatan diketahui bahwa para responden berumur antara 2260 tahun, hal ini berarti para responden tergolong petani muda produktif seperti yang dinyatakan oleh Badan Pusat Statistik (2009) yang menggolongkan usia produkif berkisar antara 15-64 tahun. Tingkat Pendidikan respondenpun bervariasi dari SD-S1, namun rata-rata pendidikan responden yaitu SMP. Tingkat pendidikan formal yang dicapai oleh individu merupakan peningkatan sumber daya manusia secara pengetahuan dan wawasan serta dapat menerima perkembangan teknologi yang berkembang, namun Pendidikan formal yang tinggi tidak menentukan perilaku individu dalam pengolahan lahan pertanian yang baik (Heliawaty dan Nurlina, 2009). Responden rata-rata bertani komoditas hortikultura hal ini didukung oleh topografi Kabupaten Garut yang berada di ketinggian lereng gunung. 
Status kepemilikin lahan responden terdiri dari, pemilik-penggarap, penyewa-penggarap dan penggarap. Berdasarkan hasil pengamatan, sebesar $66,67 \%$ responden memiliki status kepemilikan lahan pemilik penggarap, penyewa-penggarap dan penggarap masing-masing sebesa $11,11 \%$ dan $22,22 \%$. Salah satu kendala dalam budidaya pertanian adalah serangan OPT, pengendalian terhadap serangan OPT tersebut harus dilakukan agar petani tidak mengalami kerugian dan gagal panen. Pengendalian OPT bisa dilakukan dengan pestisida kimiawi atau menggunakan penerapan PHT yang aman terhadap lingkungan. Berdasarkan hasil pengamatan responden yang menggunakan penerapan PHT dalam mengendalikan OPT hanya sebesar $11,11 \%$ dan sisanya sebanyak $88,89 \%$ menggunakan pestisida kimiawi.

\section{Pengetahuan akan Pestisida dan Prinsip PHT}

Berdasarkan hasil pengamatan, sebanyak $66,67 \%$ responden tidak tahu tentang PHT. Pendekatan PHT lebih kepada upaya pengelolaan lingkungan yang tidak disukai oleh OPT, tetapi tetap menguntungkan bagi pertumbuhan tanaman. Hasil pengamatan tentang pengetahuan akan prinsip-prinsip PHT dapat dilihat pada Tabel 1.

Tabel 1. Pertanyaan Pestisida dan prinsip PHT

\begin{tabular}{|c|c|c|c|}
\hline No & Pertanyaan & Tahu & $\begin{array}{l}\text { Tidak } \\
\text { tahu }\end{array}$ \\
\hline 1. & Apakah saudara tahu te & $33,33 \%$ & $66,67 \%$ \\
\hline 2. & Apakah saudara tahu tentang APD? & $55,56 \%$ & $44,44 \%$ \\
\hline 3. & Apakah saudara tahu efek negatif pestisic & $61,11 \%$ & $38,89 \%$ \\
\hline 4. & Apakah saudara tahu pestisida nabati? & $61,11 \%$ & $38,89 \%$ \\
\hline 5. & $\begin{array}{l}\text { Apakah saudara tahu cara pembuatan pestisida } \\
\text { nabati? }\end{array}$ & $55,56 \%$ & $44,44 \%$ \\
\hline 7. & $\begin{array}{l}\text { Apakah saudara tahu bahwa penyemprotan pestisida } \\
\text { kimia yang sering dapat menyebabkan resistensi } \\
\text { hama dan penyakit? }\end{array}$ & $44,44 \%$ & $55,56 \%$ \\
\hline 8. & $\begin{array}{l}\text { Apakah saudara tahu bahwa penyemprotan pestisida } \\
\text { menjelang panen dapat menyebabkan residu pada } \\
\text { produk pertanian? }\end{array}$ & $50 \%$ & $50 \%$ \\
\hline 9. & Apakah anda tahu tanaman refugia? & 27 & $72,22 \%$ \\
\hline 10. & Apakah anda tahu manfaat tanaman refugia? & $38,89 \%$ & $61,11 \%$ \\
\hline
\end{tabular}

Sasaran PHT adalah produktivitas pertanian semakin tinggi, penghasilan dan kesejahteraan petani meningkat, populasi OPT dan kerusakan tanaman karena serangannya tetap berada di bawah ambang ekonomi serta pengurangan resiko 
penemaran lingkungan akibat penggunaan pestisida (Untung, 2007). PHT memandang bahwa untuk mengendalikan serangan hama dan penyakit tidak perlu dengan jalan memusnahkannya tetapi cukup menekan dan mengendalikan laju populasi hama dan penyakit di bawah ambang ekonomi.

Berdasarkan Tabel 1 meskipun sebanyak 61,11\% responden mengetahui akan efek negatif pestisida namun sekitar $88,89 \%$ responden masih menggunakan pestisida untuk mengendalikan OPT. Hal ini disebabkan karena 1) pestisida dapat diaplikasikan dengan mudah 2) pestisida dapat diaplikasikan di hampir setiap waktu dan tempat 3) pestisida dapat diaplikasikan dalam areal yang luas dengan waktu yang singkat 4) hasil pestisida dapat dirasakan dalam waktu yang cepat 5) pestisida mudah diperoleh dan memberikan keuntungan ekonomi dalam jangka waktu yang pendek (Kementrian Pertanian, 2011).

Minimnya pengetahuan petani akan PHT dapat diatasi dengan mengadakan SLPHT (Sekolah Lapang Pengendalian Hama Terpadu). SLPHT merupakan suatu model percontohan yang tujuannya adalah untuk melatih petani agar memiliki keahlian dalam pengendalian hama dan mampu menerapkan di lapang (Alisyahbana, 2008). Agar tujuan tersebut segera terwujud, peran seorang pemandu lapangan sangat penting dalam kegiatan SLPHT. Peran dan tugas pemandu SLPHT bukanlah mengajar peserta, melainkan untuk mengajak peserta untuk melibatkan diri di dalam proses belajar tentang PHT (Direktorat Perlindungan Tanaman Pangan, 2007). PHT dapat mempertahankan produksi yang telah dicapai sebelumnya dengan tetap mempertahankan kelestarian sumber daya alam dan peningkatan pendapatan petani. PHT berprinsip pada budidaya tanaman sehat, pelestarian musuh alami dan pengamatan mingguan mutlak untuk diterapkan dalam kegiatan pertanian.

Pelaksanaan SLPHT bertujuan untuk 1) Meningkatkan kemampuan dan ketrampilan petani di bidang pengamatan Organisme Penganggu Tanaman (OPT) dan teknologi pengendaliannya secara terpadu. 2) Meningkatkan kemampuan dan keterampilan petani dalam menganalisis agroekosistem pertanian 3) Meningkatkan kerjasama kelompok dalam berusahatani 4) Meningkatkan kualitas agroekosistem. Pelaksanaan PHT salahsatunya bisa dilakukan dengan memberikan pengetahuan kepada petani tentang tanaman refugia. Sebanyak 
$72,22 \%$ responden tidak tahu akan tanaman refugia. Refugia adalah mikrohabitat yang menyediakan tempat berlindung secara spasial dan/atau temporal bagi musuh alami hama, seperti predator dan parasitoid, serta mendukung komponen interaksi biotik pada ekosistem, seperti polinator atau serangga penyerbuk (Keppel et al., 2012). Tanaman refugia mempunyai potensi menyokong mekanisme sistem yang meliputi perbaikan ketersediaan makanan alternatif seperti nektar, serbuk sari, dan embun madu; menyediakan tempat berlindung atau iklim mikro yang digunakan serangga predator untuk bertahan melalui pergantian musim atau berlindung dari faktor-faktor ekstremitas lingkungan atau pestisida; dan menyediakan habitat untuk inang atau mangsa alternatif (Landis et al., 2000).

\section{KESIMPULAN}

Berdasarkan pengamatan yang dilakukan dapat ditarik kesimpulan sebagai berikut:

1. Pengetahuan petani akan PHT masih minim hal ini dibuktikan dengan kuesioner yang disebar, bahwa hanya sebanyak 33,33\% petani yang tahu akan PHT dan sisanya sebanyak 66,67\% tidak tahu akan PHT.

2. Sekolah Lapang Pengendalian Hama Terpadu (SLPHT) adalah salah satu cara untuk memperkenalkan PHT kepada petani. Salah satu upaya PHT yang dapat dikenalkan kepada petani adalah pemanfaatan tanaman refugia karena sebanyak $72,22 \%$ petani tidak mengetahui akan tanaman refugia.

\section{DAFTAR PUSTAKA}

Alisyahbana, Danny. 2008. Hubungan Faktor Faktor Karakteristik Petani Peserta (SLPHT) Terhadap Tingkat Penerimaan Informasi Pengendalian Hama Terpadu (PHT) Tanaman Padi.

Duriat AS, Gunawan OS, Gunaeni N. 2006. Penerapan Teknologi PHT pada Tanaman Kentang. Bandung(ID): DIPA Balitsa

Kementrian Pertanian. 2011. Pedoman Pembinaan Program Pestisida. [Internet]. [dapat diunduh di http://deptan.go.id].

Keppel, G., K.P. Van Niel, G.W. Wardell-Johnson, C.J. Yates, M.Byrne, L. Mucina, A.G.T. Schut, S.D. Hopper, dan S.E. Franklin. 2012. "Refugia: 
Identifying and understanding safe havens for biodiversity under climate change." Global Ecology and Biogeography 21 (4): 393-404. doi:10.1111/j.1466-8238.2011.00686.x

Landis, D.A., S.D. Wratten, dan G.M. Gurr. 2000. "Habitat Management to Conserve Natural Enemies of Arthropod Pests in Agriculture." Annu. Rev. Entomol. 45: 175-201

Rauf A. 1999. Persepsi dan tindakan petani kentang terhadap lalat pengorok daun, Liriomyza huidobrensis (Blanchard) (Diptera: Agromyzidae). J plant pest and diseases. 11(1): 1-13.

Yuantri MG Catur, Budia W, Henna RS. 2013. Tingkat Pengetahuan Petani dalam Menggunakan Pestisida (Studi Kasus Desa Curut Kec. Penawangan Kab Grobogan). Prosiding Seminar Nasional Pengelolaan Sumberdaya Alam dan Lingkungan. Pascasarjana Universitas Dipenogoro. Semarang. 